\title{
The assessment of TGGE for the detection of interspecific and intergeneric DNA-marker polymorphism within Solanaceae
}

\author{
S. H. Garland \\ Department of Primary Industries and Fisheries, GPO Box 46, Brisbane, Qld 4001, Australia. \\ Email: Stephen.Garland@dpi.qld.gov.au
}

\begin{abstract}
RFLP markers are currently the most appropriate marker system for the identification of uncharacterised polymorphism at the interspecific and intergeneric level. Given the benefits of a PCR-based marker system and the availability of sequence information for many Solanaceous cDNA clones, it is now possible to target conserved fragments, for primer development, that flank sequences possessing interspecific polymorphism. The potential outcome is the development of a suite of markers that amplify widely in Solanaceae. Temperature gradient gel electrophoresis (TGGE) is a relatively inexpensive gel-based system that is suitable for the detection of most single-base changes. TGGE can be used to screen for both known and unknown polymorphisms, and has been assessed here, for the development of PCR-based markers that are useful for the detection of interspecific variation within Solanaceae. Fifteen markers are presented where differences between Lycopersicon esculentum and $L$. pennellii have been detected by TGGE. The markers were assessed on a wider selection of plant species and found to be potentially useful for the identification of interspecific and intergeneric polymorphism in Solanaceous plants.
\end{abstract}

Additional keywords: tomato, potato, Solanum, capsicum, pepper.

\section{Introduction}

RFLP markers are currently the most appropriate marker system for identifying polymorphism at the interspecific and intergeneric level. Given the availability of DNA sequence information and the benefits of PCR, it is now appropriate to develop PCR-based marker systems to replace RFLP procedures. At the start of this investigation, the Solanaceae Genomics Network (SGN) (http://www.sgn.cornell.edu/markers/cos_markers. html) contained sequences for approximately 1000 conserved-ortholog-set markers (COS). COS markers are single-copy tomato EST clones that are highly conserved between tomato (Lycopersicon esculentum) and Arabidopsis. Increasing amounts of EST sequences for a range of Lycopersicon and Solanum species are also available at SGN. It is now possible to target fragments conserved within Solanaceae that flank interspecific polymorphisms, for the development of PCR-based markers for use in genetic mapping, comparative genetic mapping, or the identification of introgressed fragments (e.g. via cell fusion).

The power of temperature gradient gel electrophoresis (TGGE) to detect mutations, known and unknown, makes it a useful tool for the identification of single nucleotide polymorphism (SNP), other DNA polymorphisms, and the development of new PCR-based marker systems.
TGGE is a relatively inexpensive gel-based system and is suitable for the detection of most single-base changes (Sheffield et al. 1989).

The analysis of double-stranded DNA by TGGE (Rosenbaum and Riesner 1987) requires fragments of 100-500 bp. The fragments must possess a high-melt domain (naturally occurring GC-rich region, GC clamp, or chemical clamp) and a low-melt domain. Polyacrylamide gel electrophoresis is used to run fragments through a gradient of increasing temperature. Fragments that have a different sequence in the low-melt domain will reversibly denature into Y-shaped (non-rigid) molecules at different temperatures and therefore at different positions in the gel. Further migration is greatly reduced once the low-melt domain has denatured. Alleles with a different sequence within the lowmelt domain may then be identified by their relative positions in the gel.

Further resolution in the separation of allelles can be achieved by heteroduplex analysis (Lessa and Applebaum 1993; Qiagen 1993; Elphinstone and Baverstock 1997). When a mixture of 2 alleles is denatured and annealed, 2 types of hybrid molecules are formed (heteroduplices) along with the reformation of the original 2 molecules (homoduplices). The heteroduplexed products will have mismatched base pairing and will usually denature at lower temperatures 
than the homoduplices. Optimally, up to 4 bands will be seen when 2 alleles are heteroduplexed and analysed by TGGE. Heteroduplex/TGGE analysis could be used to screen for different alleles in populations or DNA samples, and can naturally occur in the analysis of PCR products from a heterozygous individual (Lessa and Applebaum 1993; Elphinstone and Baverstock 1997).

Currently, TGGE and related systems such as denaturing gradient gel electrophoresis (DGGE) and temporal temperature gel electrophoresis (TTGE) are frequently used to assess diversity in complex mixtures of organisms. For example, these systems have been used to study bacterial communities (Gomes et al. 2001; Brummer et al. 2003; Fouratt et al. 2003; Nishida et al. 2003; Ramirez-Saad et al. 2003; Chen and Banks 2004; Haruta et al. 2004; Henri-Dubernet etal. 2004; Luo etal. 2004; Ogier et al. 2004; Xu and Leff 2004), and eukaryotic communities (Carlos et al. 2000; Hernan-Gomez et al. 2000; Anderson and Cairney 2004; Ikenaga et al. 2004; Prakitchaiwattana et al. 2004; Savin et al. 2004). These systems are also commonly used to screen for polymorphisms in human DNA (Toliat et al. 2000; Muller et al. 2001; Katzke et al. 2002; Lage et al. 2004; Mihic-Probst et al. 2004; Saarikoski et al. 2004; Sekiguchi et al. 2004; Soufi et al. 2004) and less commonly used in wildlife and animal population genetics (Heslewood et al. 1998; Jerry and Baverstock 1998; Houlden et al. 1999; Leo and Barker 2002; da Mota et al. 2004; Westerdahl et al. 2004). The author is not aware of any publications that involve the use of TGGE, or other related systems, for the investigation of vascular plants.

The author has assessed TGGE for the development of PCR-based markers that are widely useful for the detection of interspecific variation within Solanaceae.

\section{Materials and methods}

Conserved ortholog set (COS) markers from the Solanaceae Genomics Network (SGN) (http://www.sgn.cornell.edu/markers/ cos_markers.html) were identified that possessed orthologous EST sequences for Lycopersicon esculentum (tomato), L. pennellii (wild tomato relative), Solanum tuberosum (potato), and Arabidopsis thaliana. GenBank blast searches were performed in order to identify sequences for other species, and other sequences available from SGN were included if available. Sequences were aligned using ClustalW (WWW Service at the European Bioinformatics Institute http://www.ebi.ac.uk/clustalw; Higgins et al. 1994). The comparison between $L$. esculentum and $L$. pennellii was used to identify fragments demonstrating interspecific polymorphism. Primers were designed for these fragments if the following criteria were met:

(a) the presence of suitable primer sites flanking the polymorphic regions with close to $100 \%$ conservation between the tomato species and potato;

(b) the primer sites also demonstrated moderate to good conservation with Arabidopsis;

(c) the primer sites produced a product of $80-500 \mathrm{bp}$, with preference for product sizes of $150-400 \mathrm{bp}$; (d) fragments possessed a distinct, single, melting domain, when analysed by the computer program Poland (Steger 1994), at Heinrich-Heine-Universität Düsseldorf, Institut für Physikalische Biologie, http://www.biophys.uni-duesseldorf.de/ local/POLAND/poland.html;

(e) fragments, with GC clamp, possessed distinct high- and low-melting domains; and

$(f)$ the fragment to be amplified did not contain an intron, as identified in the gDNA sequence from Arabidopsis.

It was hoped that the resulting fragments would amplify widely within Solanaceae and possibly amplify for some non-Solanaceous plants, possess interspecific variation, and with the addition of a GC clamp be suitable for analysis by TGGE.

PCR primers were designed for 38 ESTs, using the computer program Primer3 (Rozen and Skaletsky 2000). Either the forward or reverse primer was chosen for the addition of the GC clamp so as to reduce steep melting profiles at the end of the fragment, thus producing a relatively flat profile for the low melt domain (the fragment incorporating the GC clamp would possess a high- and low-melting domain). The GC clamp $5^{\prime}$-CGCCCGCCGC GCCCCGCGCCCGGCCCGCCGCCCCCGCCCC-3' (Muyzer et al. 1993) was added to the chosen primer, of a primer pair that possessed higher $\mathrm{C}$ content than $\mathrm{G}$ (especially for the $3^{\prime}$ end); or the reversed, reverse-compliment sequence 5'-GCGGGCGGCGC GGGGCGCGGGCCGGGCGGCGGGGGCGGGG-3' if the primer pair had higher $\mathrm{G}$ content than $\mathrm{C}$ content (especially at the $3^{\prime}$ end). On a few occasions the GC clamp was constructed in reverse order or with slight variations in order to reduce the chance of self-binding or primer pair interaction. Primers were synthesised by Proligo Pty Ltd, SCU, Lismore, NSW, Australia.

Primer pairs were tested for amplification using the following conditions. PCR reactions were carried out on a Perkin Elmer, Gene Amp PCR System 9700. The reaction volume was $20 \mu \mathrm{L}$ containing $1 \times$ Roche PCR Buffer, approximately $50 \mathrm{ng}$ of genomic DNA, and $188 \mu \mathrm{M}$ dNTPs. The PCR reaction mixture also included $100 \mathrm{~nm}$ of each primer, $5.5 \mathrm{~mm}$ total $\mathrm{MgCl}_{2}$, and 0.1 units of Taq DNA Polymerase (Roche). The temperature cycling conditions were $3 \mathrm{~min}$ at $94^{\circ} \mathrm{C}$; followed by 35 cycles of $94^{\circ} \mathrm{C}$ for $30 \mathrm{~s}, 56^{\circ} \mathrm{C}$ for $30 \mathrm{~s}$, and $72^{\circ} \mathrm{C}$ for $1 \mathrm{~min}$; with a final hold at $72^{\circ} \mathrm{C}$ for $1 \mathrm{~min}$. An annealing temperature of $50^{\circ} \mathrm{C}$ was used when the primers were tested on non-tomato species.

DNA was extracted from approximately $0.03 \mathrm{~g}$ of fresh leaf tissue and ground with $1 \mathrm{~mL}$ of extraction buffer at $60^{\circ} \mathrm{C}$ (Edwards et al. 1991). The extract was added to $700 \mu \mathrm{L}$ of chloroform/isoamyl alcohol $(24: 1)$, mixed, left on ice for at least half an hour, and centrifuged at $11200 \mathrm{rcf}$ for $3 \mathrm{~min}$. DNA was precipitated from the supernatant after adding 1 volume of isopropanol followed by $5 \mathrm{~min}$ centrifugation at full speed. The pellet was washed twice with $70 \%$ ethanol and resuspended in $100 \mu \mathrm{L}$ of Tris-EDTA (TE) buffer at $\mathrm{pH} 8$.

The orthologous fragments for 33 primer pairs, from $L$. esculentum (Rouge de Marmande, D.T. Brown \& Co. Ltd), L. pennellii (LA716), and an $F_{1}$ individual resulting from a cross between the 2 species, were analysed by TGGE. Five primer pairs did not amplify DNA.

PCR products were heteroduplexed on a Perkin Elmer, Gene Amp PCR System, 9700 by 2 cycles of $95^{\circ} \mathrm{C}$ for $5 \mathrm{~min}$, cooling to $50^{\circ} \mathrm{C}$ at a $5 \%$ ramp rate, and $50^{\circ} \mathrm{C}$ for $30 \mathrm{~s}$. TGGE was performed on a TGGE maxi system, Whatman Biometra. Running conditions included: $8 \%$ polyacrylamide gel $(37.5: 1)$ with $2 \%$ glycerol and $8 \mathrm{M}$ urea, $1 \times$ MOPS buffer, $200 \mathrm{~V}$ for $6.5 \mathrm{~h}$, and a parallel temperature gradient of $40-60^{\circ} \mathrm{C}$. Fragments were detected by silver staining following the procedure recommended by Whatman Biometra.

Three primer pairs, representing COS markers T1359, T1277, and T1212, were tested on a range of plant species, and 
analysed for the determination of segregation-ratio in a $F_{2}$ mapping population ( $L$. esculentum $/ L$. pennellii, $n=60$ ). The range of plant species included L. pimpinellifolium, L. hirsutum, Solanum tuberosum (potato), Solanum melongena (egg plant), Capsicum annuum, Capsicum chinense, Nicotiana tabacum (tobacco), Petunia sp. (Order Solanales, Family Solanaceae); Ipomoea batatus (sweet potato) (Order Solanales, Family Convolvulaceae); Impatiens balsamina (Family Balsaminaceae); Raphanus sativus (radish), Brassica campestris (turnip), Brassica oleracea (cabbage) (Family Brassicaceae); Pisum sativa (pea), Phaseolus vulgarus (bean) (Family Fabaceae Papilionoideae); Cucurbita pepo (pumpkin), Cucumis sativus (cucumber) (Family Cucurbitaceae); Daucus carota (carrot) (Family Apiaceae); Beta vulgarus (beet) (Family Chenopodiaceae); Abelmoschus esculentus (okra) (Family Malvaceae); and Latuca sativa (lettuce) (Family Asteraceae Lactuceae).

DNA was extracted as previously described; however, carrot and lettuce required a further ethanol precipitation and re-suspension, impatiens and okra were extracted using a Nucleospin column (Macherey-Nagel), and 4\% PVP was added to the extraction buffer for sweet potato. All gDNA preparations were tested for suitability as
PCR templates through positive amplification using internal transcribed spacer (ITS) primers 1 and 4 (White et al. 1990).

The remaining primer pairs were tested on the Solanaceous species and sweet potato. Tomato introgression lines (Eshed and Zamir 1994), possessing single chromosomal fragments from L. pennellii (LA716), of known genome location, were used to confirm the expected geneticmap position of the markers. Expected map positions were based on the Tomato_Arabidopsis synteny map (SGN: http://www.sgn.cornell. edu/maps/tomato_arabidopsis/synteny_map.html).

Those markers that amplified for Capsicum were analysed by TGGE to identify polymorphisms between $C$. annuum and $C$. chinense.

\section{Results}

Fifteen primer pairs (Table 1) produced TGGE results where alleleic differences between $L$. esculentum and L. pennellii could be detected. General characteristics of the fragments are provided in Table 2 and the relative positions of DNA bands produced by TGGE analysis are provided in Table 3 .

Table 1. Primers specific to conserved ortholog set (COS) markers, Solanaceae Genomics Network (SGN)

Amplified fragments are suitable for TGGE analysis GC Clamp 1: CGCCCGCCGCGCCCCGCGCCCGGCCCGCCGCCCCCGCCCC GC Clamp 2: GCGGGCGGCGCGGGGCGCGGGCCGGGCGGCGGGGGCGGGG GC Clamp 3: CGCCCGCCGCGCCCCGCGCCCGCCCCGCCGCCCCCGCCCG GC Clamp 4: CCCCGCCCCCGCCGCCCGGCCCGCGCCCCGCGCCGCCCGC

\begin{tabular}{|c|c|c|}
\hline $\begin{array}{l}\text { COS } \\
\text { marker }\end{array}$ & Primer name & Oligonucleotide sequence $\left(5^{\prime}-3^{\prime}\right)$ \\
\hline \multirow[t]{2}{*}{ T1208 } & GC-T1208F & (GC Clamp 1) AAAGCCATTATTCTCCCTGTAA \\
\hline & $\mathrm{T} 1208 \mathrm{R}$ & GCACCTCTAGCAAGTCCTT \\
\hline \multirow[t]{2}{*}{ T1409 } & GC-T1409F & (GC Clamp 1) CATCTTTCCCTTACTTCATGCT \\
\hline & $\mathrm{T} 1409 \mathrm{R}$ & ATCTGAATAGCTAATGCTTCGGA \\
\hline \multirow[t]{2}{*}{ T1485 } & $\mathrm{T} 1485 \mathrm{~F}$ & TGTCCAGCAAGGATTAGCTGCT \\
\hline & GC-T1485R & (GC Clamp 2) AGCTTGCGGACAGTGATGAAATT \\
\hline \multirow[t]{2}{*}{ T1361 } & GC-T1361F & (GC Clamp 2) CAGAGGATGGAAATATGGATC \\
\hline & $\mathrm{T} 1361 \mathrm{R}$ & TGAACTGCTACATTGATTAGATC \\
\hline \multirow[t]{2}{*}{ T1308 } & GC-T1308F & (GC Clamp 2) CTGTAGACATTTCAAGAGGATACTT \\
\hline & $\mathrm{T} 1308 \mathrm{R}$ & TGTCCTGGGTCATATAAAAGATG \\
\hline \multirow[t]{2}{*}{$\mathrm{T} 1181$} & $\mathrm{~T} 1181 \mathrm{~F}$ & GGGAAACTTCCTAAGCATAATA \\
\hline & GC-T1181R & (GC Clamp 1) CAGGATACTCAATCACACTCCA \\
\hline \multirow[t]{2}{*}{$\mathrm{T} 1510$} & GC-T1510F & (GC Clamp 2) ATCGAATCCATTGCTGTTGG \\
\hline & $\mathrm{T} 1510 \mathrm{R}$ & CCAGCTGAAGAAGGGTAAGAGTT \\
\hline \multirow[t]{2}{*}{ T1277 } & GC-T1277F & (GC Clamp 1) GGTAATGTAAATGCACCTTATGAA \\
\hline & $\mathrm{T} 1277 \mathrm{R}$ & TCAACGACAGATGACTGTGC \\
\hline \multirow[t]{2}{*}{$\mathrm{T} 1581$} & $\mathrm{~T} 1581 \mathrm{~F}$ & TGAAGAAAGCCGTGATGCT \\
\hline & GC-T1581R & (GC Clamp 3) CTCTAGTAGCATACATAATTGC \\
\hline \multirow[t]{2}{*}{ T1359 } & $\mathrm{T} 1359 \mathrm{~F}$ & AAGGAGGAGGAATTTGTGTT \\
\hline & GC-T1359R & (GC Clamp 4) CGGTTAAACTCATCAGAATCAT \\
\hline \multirow[t]{2}{*}{ T1212 } & $\mathrm{T} 1212 \mathrm{~F}$ & AGAAAATCACAATGGCAGCA \\
\hline & GC-T1212R & (GC Clamp 1) GAGACAACATCAAGTTTCTTCTGAT \\
\hline \multirow[t]{2}{*}{ T1482 } & GC-T1482F & (GC Clamp 1) CACAACTCCTGGCTTGCAAAT \\
\hline & $\mathrm{T} 1482 \mathrm{R}$ & CTGAAACTGGCACTTGTTCACT \\
\hline \multirow[t]{2}{*}{ T0736 } & GC-T0736F & (GC Clamp 1) TCTATATCAACCATGTACGGATTC \\
\hline & T0736R & ATTTTGGAGATAAGGACCGTATT \\
\hline \multirow[t]{2}{*}{ T1125 } & GC-T1125F & (GC Clamp 2) ATGATTTTTTGGCTGGGAGACT \\
\hline & $\mathrm{T} 1125 \mathrm{R}$ & CCTGGAGAATGCAAAGTGGTTT \\
\hline \multirow[t]{2}{*}{ T1460 } & GC-T1460F & (GC Clamp 1) TTGCAGTGGAGATGAAACAGC \\
\hline & T1460R & GCTACGTTCCACCAGCTGAA \\
\hline
\end{tabular}


Table 2. General characteristics of PCR products of conserved ortholog set (COS) based markers, Solanaceae Genomics Network (SGN)

\begin{tabular}{|c|c|c|c|c|c|c|}
\hline $\begin{array}{l}\text { COS } \\
\text { marker }\end{array}$ & $\begin{array}{l}\text { Exp. size } \\
(\mathrm{bp})^{\mathrm{A}}\end{array}$ & $\begin{array}{l}\text { Obs. size as } \\
\text { expected }^{\mathrm{B}}\end{array}$ & $\begin{array}{l}\text { No. of } \\
\text { SNPC }^{C}\end{array}$ & $\begin{array}{l}\text { SNP positions relative to GC clamp } \\
\text { (GC) }\end{array}$ & $\begin{array}{c}\text { Tomato } \\
\text { chromosome no. }\end{array}$ & $\% \mathrm{GC}$ \\
\hline T1208 & 410 & Yes & 5 & (GC)-71-80-153-333-357- & 1 & 38 \\
\hline T1409 & 130 & Yes & 3 & (GC)-32-101-107- & 1 & 46 \\
\hline $\mathrm{T} 1485$ & 243 & Yes & 4 & $-221-196-174-27-(\mathrm{GC})$ & 1 & 43 \\
\hline T1361 & 180 & Yes & 2 & (GC)-146-151- & 2 & 41 \\
\hline T1308 & 135 & $\mathrm{No}^{\mathrm{D}}$ & 2 & Not applicable & 3 & - \\
\hline $\mathrm{T} 1181$ & 190 & Yes & 2 & $-164-76-(\mathrm{GC})$ & 5 & 42 \\
\hline $\mathrm{T} 1510$ & 182 & Yes & 2 & (GC)-51-54- & 7 & 39 \\
\hline $\mathrm{T} 1277$ & 124 & Yes & 2 & (GC)-57-104 & 8 & 41 \\
\hline $\mathrm{T} 1581$ & 143 & $\mathrm{No}^{\mathrm{E}}$ & 3 & Not applicable & 8 & - \\
\hline T1359 & 149 & Yes & 3 & $-99-87-39-(\mathrm{GC})$ & 8 & 44 \\
\hline $\mathrm{T} 1212$ & $427^{\mathrm{F}}$ & Yes & $3^{\mathrm{G}}$ & -indel(407-393)-333-308-120-(GC) & 9 & 38 \\
\hline $\mathrm{T} 1482$ & 242 & Yes & 2 & (GC)-64-146- & 10 & 38 \\
\hline T0736 & 192 & Yes & 3 & (GC)-25-45-159- & 10 & 45 \\
\hline $\mathrm{T} 1125$ & 222 & Yes & 4 & (GC)-38-113-165-166- & 11 & 32 \\
\hline $\mathrm{T} 1460$ & 88 & Yes & 2 & (GC)-34-48- & 11 & 45 \\
\hline
\end{tabular}

${ }^{\mathrm{A}}$ Expected size does not include GC clamp.

${ }^{\mathrm{B}}$ Observed size is based on assessment by agarose gel electrophoresis.

${ }^{\mathrm{C}}$ Number of single nucleotide polymorphisms between orthologueous sequence for L. esculentum and L. pennellii as supplied by the SGN.

D $>200 \mathrm{bp}$.

${ }^{\mathrm{E}}$ About $250 \mathrm{bp}$.

${ }^{\mathrm{F}} 427 \mathrm{bp}$ in L. pennellii, $412 \mathrm{bp}$ in L. esculentum.

GPlus 1 indel (insertion/deletion) of $15 \mathrm{bp}$.

Table 3. TGGE Gel relative positions for PCR-amplified DNA bands

Bands represent alleles and heteroduplices for L. esculentum and L. pennellii, for various conserved ortholog set (COS)-based markers. The gel position is presented as the temperature for a given position within the experimental gradient of $40-60^{\circ} \mathrm{C}$ as determined on a single gel. The band positions and relative positions between bands will vary slightly between runs

\begin{tabular}{lccl}
\hline $\begin{array}{l}\text { COS } \\
\text { marker }\end{array}$ & $\begin{array}{c}\text { Rel. pos. of } \\
\text { L. esculentum } \\
\text { allele }\left({ }^{\circ} \mathrm{C}\right)\end{array}$ & $\begin{array}{c}\text { Rel. pos. of } \\
\text { L. pennellii } \\
\text { allele }\left({ }^{\circ} \mathrm{C}\right)\end{array}$ & $\begin{array}{c}\text { Rel. pos. of } \\
\text { heteroduplex } \\
\text { bands }\left({ }^{\circ} \mathrm{C}\right)\end{array}$ \\
\hline $\mathrm{T} 1208$ & 47.8 & 47.1 & 45.1 and 43.6 \\
$\mathrm{~T} 1409$ & 55.9 & 53.6 & 44.0 and 42.8 \\
$\mathrm{~T} 1485^{\mathrm{A}}$ & 48.3 & 49.4 & 45.0 and 44.4 \\
$\mathrm{~T} 1361$ & 47.3 & 48.8 & 45.5 \\
$\mathrm{~T} 1308$ & 45.4 & 45.1 & 42.9 and 42.0 \\
$\mathrm{~T} 1181$ & 49.4 & 50.0 & 49.1 \\
$\mathrm{~T} 1510$ & 48.1 & 47.8 & 46.3 and 46.0 \\
$\mathrm{~T} 1277^{\mathrm{B}}$ & 51.6 & 50.5 & 49.0 and 47.5 \\
$\mathrm{~T} 1581$ & 51.3 & 50.8 & None \\
$\mathrm{T} 1359$ & 52.9 & 52.0 & 48.0 and 47.3 \\
$\mathrm{~T} 1212$ & 46.1 & 46.6 & 41.6 \\
$\mathrm{~T} 1482$ & 47.3 & 46.6 & 45.5 and 44.4 \\
$\mathrm{~T} 0736$ & 52.9 & 51.3 & 49.1 and 47.6 \\
$\mathrm{~T} 1125$ & 43.8 & 43.1 & 42.3 and 41.9 \\
& & & (double bands) \\
T1460 & 54.5 & 55.3 & 50.0 and 48.9 \\
\hline
\end{tabular}

${ }^{\mathrm{A}}$ A double-banding pattern was occasionally produced for putative alleles of this marker.

${ }^{\mathrm{B}} \mathrm{A}$ double-banding pattern was produced for putative alleles of this marker.
The results represent a success rate of $39.5 \%$ for the conversion of COS DNA sequences into useful TGGE-based markers where differences between orthologous fragments of $L$. esculentum and $L$. pennellii could be detected. The success rate improves to $45.5 \%$ if consideration is only given to primer pairs that successfully amplified PCR product.

The results concerning the mapping of markers using introgression lines are presented in Table 4. All analysed markers (no results for T1361) were located at or near the expected genome location, except for the markers representing T1212 and T1277. An important introgression line needed for T1212 was not available, making a positive result impossible. A L. pennellii allele was not detected in the introgression line expected to contain the T1277 marker. In fact, all 3 introgression lines analysed, which in total cover all of chromosome 8 , delivered negative results. The results suggest that the marker representing T1277 is not on chromosome 8 .

The assessment of the markers for PCR amplification in a range of Solanaceous species and sweet potato (order Solanales) is presented in Table 5. The results indicate that the 7 primer pairs representing COS markers T1208, T1485, T1277, T1581, T1359, T1212, and T1482 amplified for all of the Solanaceous species analysed. Another 4 primer pairs (T1409, T1181, T0736, T1125) either did not amplify, or poorly amplified, for Petunia sp. but amplified for all other Solanaceous species. Petunias are more distantly related to tomato than the other Solanaceous species analysed. 
Table 4. Mapping of markers using introgression lines (IL)

\begin{tabular}{lccc}
\hline $\begin{array}{l}\text { COS } \\
\text { marker }\end{array}$ & $\begin{array}{c}\text { Exp. genome } \\
\text { location } \\
\left.\text { (IL }^{\mathrm{A}}\right)\end{array}$ & IL analysed & $\begin{array}{c}\text { Obs. genome } \\
\text { location (IL with } \\
\text { L. pennellii alleles) }\end{array}$ \\
\hline T1208 & $1-1 \& 1-2$ & $1-1,1-2,1-3$ & $1-2^{\mathrm{B}}$ \\
T1409 & $1-2$ & $1-1,1-2,1-3$ & $1-2$ \\
T1485 & $1-3$ & $1-1,1-2,1-3$ & $1-3$ \\
T1361 & $2-3$ & Nil & Nil \\
T1308 & $3-4 \& 3-5$ & $3-2,3-4,3-5$ & $3-4 \& 3-5$ \\
T1181 & $5-1$ & $5-1,5-2,5-3$ & $5-1$ \\
T1510 & $7-2,7-3,7-4$ & $7-1$ to 7-4 & $7-2 \& 7-3^{\mathrm{B}}$ \\
T1277 & $8-1$ & $8-1,8-2,8-3$ & Nil \\
T1581 & $8-2 \& 8-3$ & $8-1,8-2,8-3$ & $8-2 \& 8-3$ \\
T1359 & $8-3$ & $8-1,8-2,8-3$ & $8-3$ \\
T1212 & $9-3$ and/or 9-2 & $9-1 \& 9-3$ & Nil \\
T1482 & $10-1$ and/or 10-2 & $10-1,10-2,10-3$ & $10-1 \& 10-2$ \\
T0736 & $10-2$ & $10-1,10-2,10-3$ & $10-2$ \\
T1125 & $11-1 \& 11-2$ & $11-1,11-2,11-3$ & $11-1 \& 11-2$ \\
T1460 & $11-2 \& 11-3$ & $11-1,11-2,11-3$ & $11-2^{\mathrm{B}}$ \\
\hline
\end{tabular}

${ }^{\mathrm{A}}$ Introgression lines (L. esculentum) contain single fragments introgressed from L. pennellii. (Eshed and Zamir 1994). The first number represents the chromosome, and the number after the dash represents the introgressed fragment. Lines from individual chromosomes are sequentially numbered so that fragments are adjoining. Adjoining fragments overlap. If 2 or more lines are indicated, the genome location is at the overlapping region.

${ }^{\mathrm{B}}$ The marker is close to the expected genome location but the difference between the expected and observed results may be due to imprecision in the genetic map used to position the marker or a problem with the introgression line that unexpectedly returned a negative result.

${ }^{\mathrm{C}}$ This result is not conclusive as there may be a problem with introgression line 8-1, or the marker sequence may not correspond to that of the RFLP probe used for the genetic mapping.

${ }^{\mathrm{D}}$ Introgression line 9-2 was not available for testing and the marker may be contained within the associated fragment.
Primer pairs representing T1361 and T1510 did not amplify for Petunia and the Capsicum species. The primer pair of T1460 did not amplify for eggplant and tobacco. Only the primer pair representing T1359 amplified in sweet potato.

The primer pair representing T1359 successfully amplified in all solanaceous samples and for sweet potato, and the resulting PCR products were successfully analysed by TGGE (Petunia sp. not included in TGGE analysis) (Fig. 1a). The results suggest that more than 2 loci, or 2 loci with more than 2 alleles, amplified in potato and sweet potato, which is consistent with the polyploid nature of these species; and 2 loci or alleles amplified for tobacco and possibly L. hirsutum. Only 1 locus was apparent for the other species. No differences in melting behaviour were detected between $L$. esculentum and L. pimpinellifolium, and between C. annuum and C. chinense. Differences were observed for all other comparisons.

The L. pennellii and L. esculentum alleles (Fig. $1 b$ ) were found to segregate in a $F_{2}$ mapping population (Fig. 1c). Segregation ratio was consistent with that produced by a single locus, as tested by $\chi^{2}(0.05$, d.f. $=2)$ analysis $(P>0.1)$. The observed segregation ratio, homozygous for the $L$. pennellii allele: heterozygous: homozygous for the L. esculentum allele, was $10: 33: 17(n=60)$.

The primer pair representing T1277 successfully amplified in all solanaceous samples and for bean, and the resulting PCR products were successfully analysed by TGGE (Petunia sp. not included in TGGE analysis) (Fig. 2a). A double-banding pattern was observed for all alleles including heteroduplexed products of $L$. esculenum and L. pennellii. As no heteroduplices were observed for

Table 5. Test of markers for PCR amplification in various plant species from the order Solanales

All markers amplified for Lycopersicon esculentum, L. pennellii, L. pimpinellifolium, L. hirsutum, and Solanum tuberosum

\begin{tabular}{lcccccc}
\hline $\begin{array}{l}\text { COS } \\
\text { marker }\end{array}$ & $\begin{array}{c}\text { Solanum } \\
\text { melongena }\end{array}$ & $\begin{array}{c}\text { Capsicum } \\
\text { annuum }\end{array}$ & $\begin{array}{c}\text { Capsicum } \\
\text { chinense }\end{array}$ & $\begin{array}{c}\text { Nicotiana } \\
\text { tabacum }\end{array}$ & $\begin{array}{c}\text { Petunia } \\
\text { sp. }\end{array}$ & $\begin{array}{c}\text { Ipomoea } \\
\text { batatus }\end{array}$ \\
\hline T1208 & Yes & Yes & Yes & Yes & Yes & No \\
T1409 & Yes & Yes & Yes & Yes & No & No \\
T1485 & Yes & Yes & Yes & Yes & Yes & No \\
T1361 & Yes & Poor & Poor & Yes & Poor & No \\
T1308 & Yes & Yes & Yes & Poor & Yes & No \\
T1181 & Yes & Yes & Yes & Yes & Poor & No \\
T1510 & Yes & Poor & Poor & Yes & Poor & No \\
T1277 & Yes & Yes & Yes & Yes & Yes & No \\
T1581 & Yes & Yes & Yes & Yes & Yes & No \\
T1359 & Yes & Yes & Yes & Yes & Yes & Yes \\
T1212 & Yes & Yes & Yes & Yes & Yes & No \\
T1482 & Yes & Yes & Yes & Yes & Yes & No \\
T0736 & Yes & Yes & Yes & Yes & No & No \\
T1125 & Yes & Yes & Yes & Yes & No & No \\
T1460 & No & Yes & Yes & No & Yes & No \\
\hline A & & & & & &
\end{tabular}

${ }^{\mathrm{A}}$ Also amplified in Phaseolus vulgarus. 
(a)

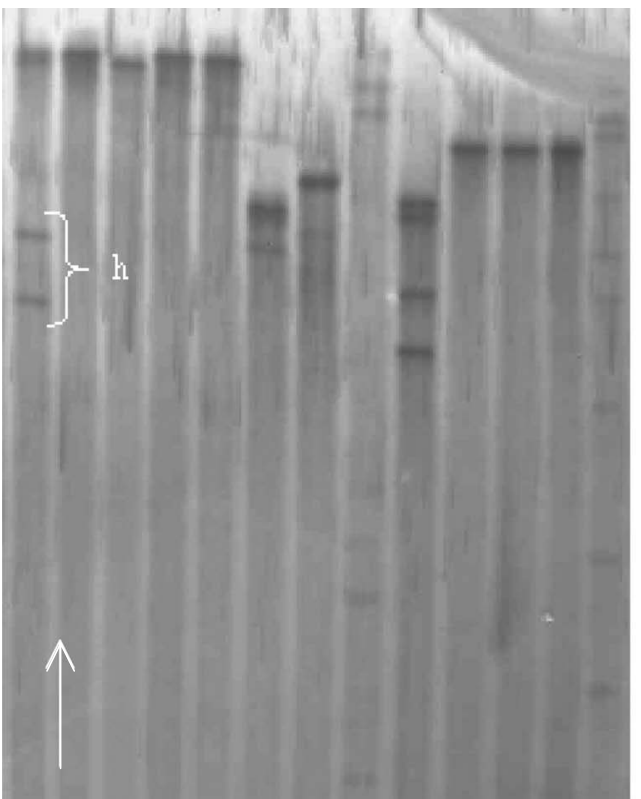

$\begin{array}{lllllllllllll}1 & 2 & 3 & 4 & 5 & 6 & 7 & 8 & 9 & 10 & 11 & 12 & 13\end{array}$ (b)

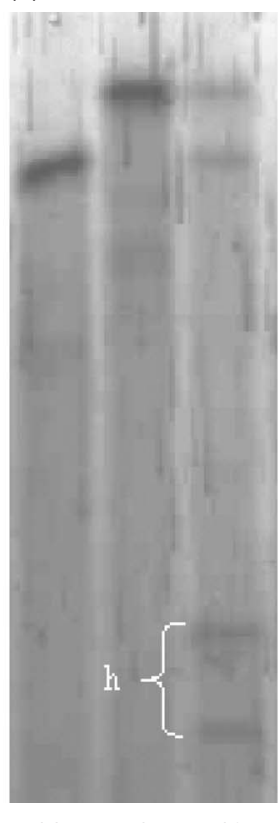

$(c)$

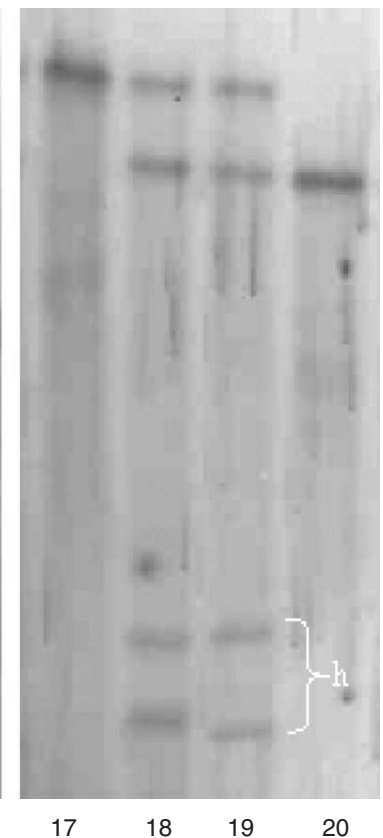

Fig. 1. TGGE analysis of PCR products representing COS-marker T1359. Fragment size excluding GC clamp is $149 \mathrm{bp}$ for $L$. esculentum and L. pennellii. There was no apparent difference in fragment size for all species, as observed by agarose gel electrophoresis. The arrow indicates the direction of band migration and of increasing temperature. (h) Heteroduplex bands. $(a, b)(1) \mathrm{F}_{1}$ L. esculentum/L. pennellii, (2) L. esculentum, (3) L. pennellii, (4) L. esculentum heteroduplexed with L. pimpinellifolium, (5) L. pimpinellifolium, (6) L. hirsutum, (7) egg plant, (8) potato, (9) tobacco, (10) C. annuum heteroduplexed with $C$. chinense, (11) C. annuum, (12) C. chinense, (13) sweet potato, (14) L. pennellii, (15) L. esculentum, (16) $\mathrm{F}_{1}$ L. esculentum/L. pennellii. (c) (17-20) Alleles segregating in an $\mathrm{F}_{2}$ mapping population, L. esculentum/L. pennellii.

(a)

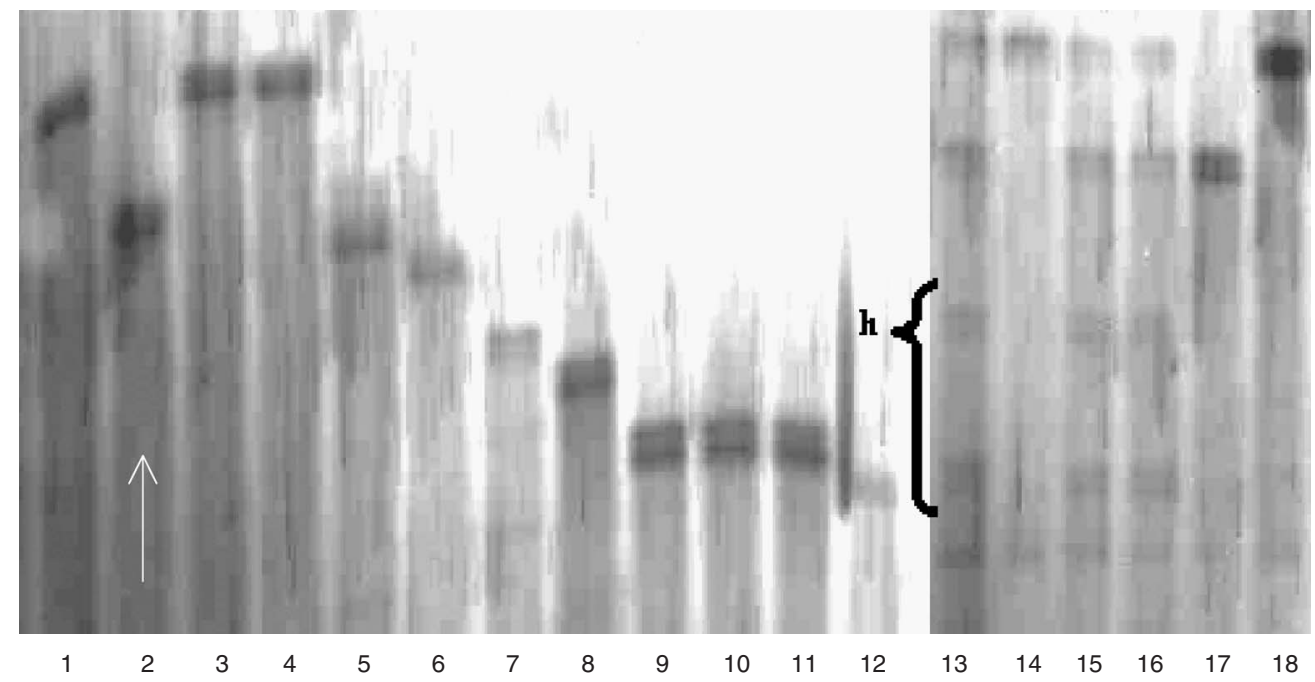

Fig. 2. TGGE analysis of PCR products representing COS-marker T1277. Fragment size excluding GC clamp is $124 \mathrm{bp}$ for L. esculentum and L. pennellii. There was no apparent difference in fragment size for all species, as observed by agarose gel electrophoresis. The arrow indicates the direction of band migration and of increasing temperature. (h) Heteroduplex bands. (a) (1) L. esculentum, (2) L. pennellii, (3) L. esculentum heteroduplexed with L. pimpinellifolium, (4) L. pimpinellifolium, (5) L. hirsutum, (6) egg plant, (7) potato, (8) tobacco, (9) C. annuum heteroduplexed with C. chinense, (10) C. annuum, (11) C. chinense, (12) bean. (b) (13-18) Alleles segregating in an $\mathrm{F}_{2}$ mapping population, L. esculentum/L. pennellii. 
individual species, the double-banding pattern is unlikely to be due to the amplification of multiple loci. No differences in melting behaviour were detected between L. esculentum and $L$. pimpinellifolium, and between $C$. annuum and $C$. chinense. Differences were observed for all other comparisons (Fig. 2a).

The L. pennellii and L. esculentum alleles were found to segregate in a $\mathrm{F}_{2}$ mapping population (Fig. $2 b$ ). Segregation ratio was consistent with that produced by a single locus, although segregation was skewed in favour of the $L$. pennellii allele, as tested by $\chi^{2}(0.05$, d.f. $=2)$ analysis $(P=0.1)$. The observed segregation ratio, homozygous for the L. pennellii allele: heterozygous: homozygous for the $L$. esculentum allele, was $22: 24: 14(n=60)$.

The primer pair representing T1212 successfully amplified product in all solanaceous samples, and the resulting PCR products were successfully analysed by TGGE (Petunia sp. not included in TGGE analysis) (Fig. 3a). Two distinct bands were observed for eggplant and the 2 Capsicum species. No heteroduplex bands were obvious, and therefore it is not apparent if these bands represented 2 separate loci or alleles, or were the consequence of the techniques used and characteristics unique to those DNA samples. Four bands were observed for tobacco, consistent with the amplification of 2 loci or alleles. No differences in melting behaviour were detected between L. esculentum and L. pimpinellifolium. Differences were observed for all other comparisons including the production of heteroduplicies when PCR products of $C$. annuum and $C$. chinense were mixed.
The L. pennellii and L. esculentum alleles were found to segregate in a $\mathrm{F}_{2}$ mapping population (Fig. $3 b$ ). Segregation ratio was consistent with that produced by a single locus, as tested by $\chi^{2}(0.05$, d.f. $=2)$ analysis $(P>0.7)$. The observed segregation ratio, homozygous for the $L$. pennellii allele: heterozygous: homozygous for the $L$. esculentum allele, was $17: 30: 13(n=60)$.

Five of the 13 markers that amplified for Capsicum were found to be polymorphic between $C$. annuum and $C$. chinense by TGGE analysis (data not shown). These markers were T1212, T1482, T0736, T1125, and T1460.

\section{Discussion}

Temperature gradient gel electrophoresis (TGGE) proved to be a successful tool for the identification of expected polymorphism between orthologous fragments representing putative COS-sequences for $L$. esculentum and L. pennellii. Of the markers possessing expected polymorphism that amplified by PCR, $45.5 \%$ were successfully analysed by TGGE. TGGE therefore provides a PCR-based alternative to RFLP or CAPS-based mapping of COS markers for crosses involving $L$. esculentum and L. pennellii.

TGGE also proved its utility for the identification of unknown interspecific-polymorphism for Lycopersicon and Capsicum, for the markers developed from COS sequences. Differences could be detected between alleles of L. esculentum and L. hirsutum, and L. pennellii and L. hirsutum, for the markers T1212, T1277, and T1359. For the 13 markers that amplified in Capsicum, 5 recorded a (a)

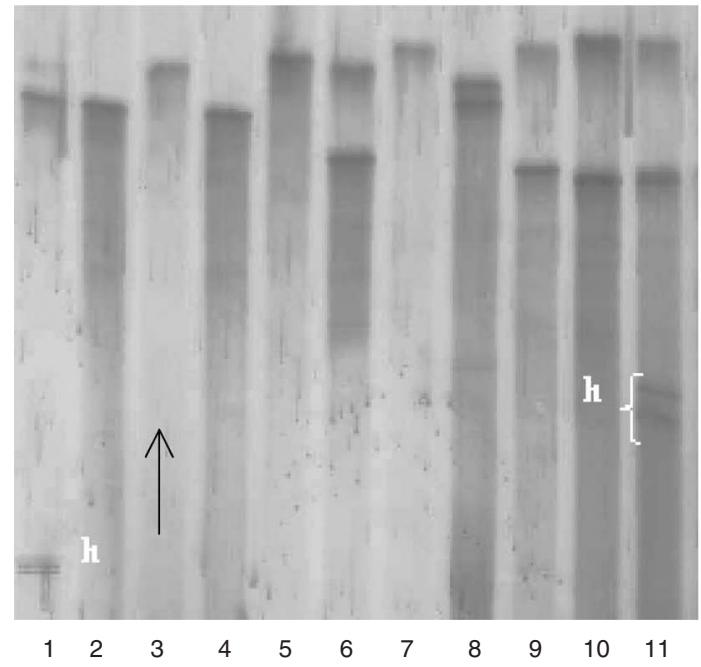

(b)

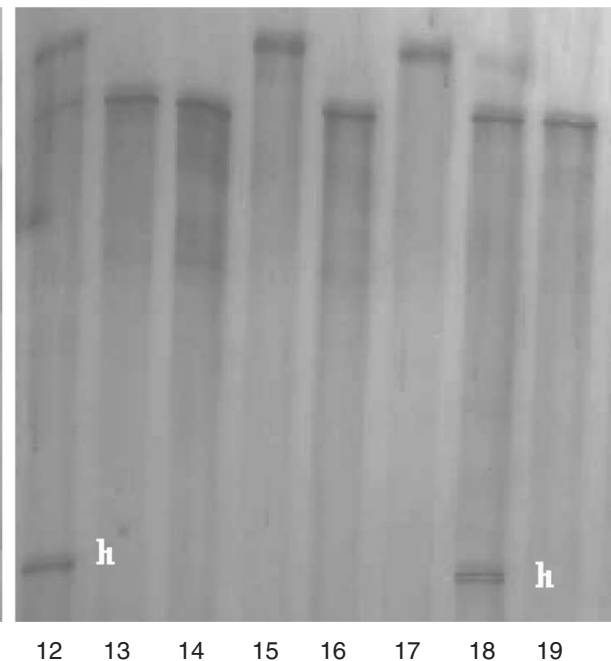

Fig. 3. TGGE analysis of PCR products representing COS-marker T1212. Fragment size excluding GC clamp is $415 \mathrm{bp}$ in L. esculentum and $427 \mathrm{bp}$ in L. pennellii. Fragment size for the other species is similar, as observed by agarose gel electrophoresis. The arrow indicates the direction of band migration and of increasing temperature. (h) Heteroduplex bands. (a) (1) $\mathrm{F}_{1}$ L. esculentum/L. pennellii, (2) L. esculentum, (3) L. pennellii, (4) L. pimpinellifolium, (5) L. hirsutum, (6) egg plant, (7) potato, (8) tobacco, (9) C. annuum, (10) C. chinense, (11) C. annuum heteroduplexed with C. chinense. (b) (12-19) Alleles segregating in an $\mathrm{F}_{2}$ mapping population, L. esculentum/L. pennellii. 
difference between the Capsicum species. This study has demonstrated that TGGE is an efficient method for the development of PCR-based markers when DNA sequences are only available for related species or genera, and not available for the species of interest.

With respect to the 3 markers representing T1212, T1277, and T1359, no differences were detected between the closely related species of $L$. esculentum and L. pimpinellifolium. Similarly, not all markers tested identified differences between the Capsicum species. The results indicate that the marker system will not be useful for all interspecific comparisons.

The potential usefulness of the developed markers for amplification within Solanaceae has also been demonstrated. Seven markers amplified for the 5 Solanaceous genera tested (Lycopersicon, Solanum, Nicotiana, Capsicum, Petunia), and the 2 markers developed from T1359 and T1277 amplified outside of the family. The marker corresponding to COS marker T1359, amplified in Ipomoea batatus (sweet potato), a plant that belongs to Family Convolvulaceae. Solanaceae and Convolvulaceae are contained within the same Order, Solanales. Amplification across these 2 families adds support to the utility of this marker within Solanaceae. In addition, the markers may amplify in a wider range of species with further optimisation.

The marker representing T1277 was the only marker identified as not being located at, or near, the expected genome location. This result should not be considered conclusive, as the supplied introgression line (8-1) may not have contained the appropriate $L$. pennellii fragment. Alternatively, the results may indicate that the sequence used by this author, to design the primers, did not represent the RFLP probe used to genetically map COS marker T1277 (SGN: Tomato_Arabidopsis synteny map).

The general success of this investigation indicates that the 15 markers will provide a useful resource for the identification of interspecific polymorphism in Solanaceae. This is particularly the case for those species for which large amounts of EST data are not available. For example, the markers, and new markers yet to be developed, will provide useful PCR-based markers for tomato mapping and breeding populations involving $L$. hirsutum and probably other wild relatives. In the case of cell fusion lines, the marker system will be very useful for the identification of interspecific or intergeneric fragments.

\section{Acknowledgments}

This research was funded by the Queensland Government's Department of Primary Industries and Fisheries. The $\mathrm{F}_{2}$ mapping population was kindly supplied by Des McGrath and Ian Walker, Queensland Government's Department of Primary Industries and Fisheries. The introgression lines were kindly supplied by the Tomato Genetics Resource
Center, University of California, Davis. Thank you to Dr Mandy Christopher and Dr Wendy Lawson of the Queensland Government's Department of Primary Industries and Fisheries, for their helpful review of the manuscript.

\section{References}

Anderson IC, Cairney JWG (2004) Diversity and ecology of soil fungal communities: increased understanding through the application of molecular techniques. Environmental Microbiology 6, 769-779. doi: 10.1111/j.1462-2920.2004.00675.x

Brummer IHM, Felske A, Wagner-Dobler I (2003) Diversity and seasonal variability of beta-proteobacteria in biofilms of polluted rivers: analysis by temperature gradient gel electrophoresis and cloning. Applied and Environmental Microbiology 69, 4463-4473. doi: 10.1128/AEM.69.8.4463-4473.2003

Carlos AA, Baillie BK, Maruyama T (2000) Diversity of dinoflagellate symbionts (zooxanthellae) in a host individual. Marine Ecology Progress Series 195, 93-100.

Chen YC, Banks MK (2004) Bacterial community evaluation during establishment of tall fescue (Festuca arundinacea) in soil contaminated with pyrene. International Journal of Phytoremediation 6, 227-238. doi: 10.1080/16226510490496410

Edwards K, Johnstone C, Thompson C (1991) A simple and rapid method for the preparation of plant genomic DNA for PCR analysis. Nucleic Acids Research 19, 1349.

Elphinstone MS, Baverstock PR (1997) Detecting mitochondrial genotypes by temperature gradient gel electrophoresis and heteroduplex analysis. BioTechniques 23, 982-986.

Eshed Y, Zamir D (1994) A genomic library of Lycopersicon pennellii in L. esculentum: a tool for fine mapping of genes. Euphytica 79, 175-179. doi: 10.1007/BF00022516

Fouratt MA, Rhodes JS, Smithers CM, Love NG, Stevens AM (2003) Application of temperature gradient gel electrophoresis to the characterization of a nitrifying bioaugmentation product. FEMS Microbiology Ecology 43, 277-286. doi: 10.1016/S01686496(02)00431-2

Gomes NCM, Heuer H, Schonfeld J, Costa R, Mendonca-Hagler L, Smalla K (2001) Bacterial diversity of the rhizosphere of maize (Zea mays) grown in tropical soil studied by temperature gradient gel electrophoresis. Plant and Soil 232, 167-180. doi: 10.1023/A:1010350406708

Haruta S, Kondo M, Nakamura K, Chanchitpricha C, Aiba H, Ishii M, Igarashi Y (2004) Succession of a microbial community during stable operation of a semi-continuous garbage-decomposting system. Journal of Bioscience and Bioengineering 98, 20-27.

Henri-Dubernet S, Desmasures N, Gueguen M (2004) Culturedependent and culture-independent methods for molecular analysis of the diversity of lactobacilli in "Camembert de Normandie" cheese. Le Lait 84, 179-189. doi: 10.1051/lait:2003037

Hernan-Gomez S, Espinosa JC, Ubeda JF (2000) Characterization of wine yeasts by temperature gradient gel electrophoresis (TGGE). FEMS Microbiology Letters 193, 45-50. doi: 10.1016/S03781097(00)00452-3

Heslewood MM, Elphinstone MS, Tidemann SC, Baverstock PR (1998) Myoglobin intron variation in the Gouldian finch Erythrura gouldiae assessed by temperature gradient gel electrophoresis. Electrophoresis 19, 142-151.

Higgins D, Thompson J, Gibson T, Thompson JD, Higgins DG, Gibson TJ (1994) CLUSTAL W: improving the sensitivity of progressive multiple sequence alignment through sequence weighting, positionspecific gap penalties and weight matrix choice. Nucleic Acids Research 22, 4673-4680. 
Houlden BA, Costello BH, Sharkey D, Fowler EV, Melzer A, Ellis W, Carrick F, Baverstock PR, Elphinstone MS (1999) Phylogeographic differentiation in the mitochondrial control region in the koala, Phascolarctos cinereus (Goldfuss 1817). Molecular Ecology 8, 999-1011. doi: 10.1046/j.1365-294x.1999.00656.x

Ikenaga M, Asakawa S, Muraoka Y, Kimura M (2004) Community structure of eukaryotes in rice roots estimated by PCR-DGGE pattern and sequence analysis. Soil Science and Plant Nutrition 50, 583-589.

Jerry DR, Baverstock PR (1998) Consequences of a catadromous lifestrategy for levels of mitochondrial DNA differentiation among populations of the Australian bass, Macquaria novemaculeata. Molecular Ecology 7, 1003-1013. doi: 10.1046/j.1365-294x. 1998.00418.x

Katzke S, Booms P, Tiecke F, Palz M, Pletschacher A, et al. (2002) TGGE screening of the entire FBN1 coding sequence in 126 individuals with Marfan syndrome and related fibrillinopathies. Human Mutation 20, 197-208. doi: 10.1002/humu.10112

Lage PA, Albuquerque C, Sousa RG, Cravo ML, Salazar M, et al. (2004) Association of colonic endometrial carcinomas in Portuguese families with hereditary nonpolyposis colorectal carcinoma significantly increases the probability of detecting a pathogenic mutation in mismatch repair genes, primarily the MSH2 gene. Cancer 101, 172-177. doi: 10.1002/cncr.20320

Leo NP, Barker SC (2002) Intragenomic variation in ITS2 rDNA in the louse of humans, Pediculus humanus: ITS2 is not a suitable marker for population studies in this species. Insect Molecular Biology 11, 651-657. doi: 10.1046/j.1365-2583.2002.00367.x

Lessa EP, Applebaum G (1993) Screening techniques for detecting allelic variation in DNA sequences. Molecular Ecology 2, 119-129.

Luo HF, Qi HY, Zhang HX (2004) Assessment of the bacterial diversity in fenvalerate-treated soil. World Journal of Microbiology and Biotechnology 20, 509-515. doi: 10.1023/B:WIBI.0000040401.46606.a4

Mihic-Probst D, Perren A, Schmid S, Saremaslani P, Komminoth P, Heitz PU (2004) Absence of BRAF gene mutations differentiates Spitz nevi from malignant melanoma. Anticancer Research 24, 2415-2418.

da Mota AF, Martinez ML, Coutinho LL (2004) Genotyping BoLA-DRB3 alleles in Brazilian Dairy Gir cattle (Bos indicus) by temperature-gradient gel electrophoresis (TGGE) and direct sequencing. European Journal of Immunogenetics 31, 31-35. doi: $10.1111 / \mathrm{j} .1365-2370.2004 .00438 . \mathrm{x}$

Muller P, Ostwald C, Puschel K, Brinkmann B, Plath F, et al. (2001) Low frequency of p53 and ras mutations in bile of patients with hepato-biliary disease: a prospective study in more than 100 patients. European Journal of Clinical Investigation 31, 240-247. doi: 10.1046/j.1365-2362.2001.00800.x

Muyzer G, DeWaal EC, Uitterlinden AG (1993) Profiling of complex microbial populations by denaturing gradient gel electrophoresis analysis of polymerase chain reaction-amplified genes coding for 16S rRNA. Applied and Environmental Microbiology 59, 695-700.

Nishida T, Fujimura T, Omasa T, Katakura Y, Suga K, Shioya S (2003) Changes in microflora during composting of an aquatic plant, Brazilian elodea. Journal of Chemical Engineering of Japan 36, 1201-1205. doi: 10.1252/jcej.36.1201

Ogier JC, Lafarge V, Girard V, Rault A, Maladen V, Gruss A, Leveau JY, Delacroix-Buchet A (2004) Molecular fingerprinting of dairy microbial ecosystems by use of temporal temperature and denaturing gradient gel electrophoresis. Applied and Environmental Microbiology 70, 5628-5643. doi: 10.1128/AEM.70.9.56285643.2004
Prakitchaiwattana CJ, Fleet GH, Heard GM (2004) Application and evaluation of denaturing gradient gel electrophoresis to analyse the yeast ecology of wine grapes. FEMS Yeast Research 4, 865-877. doi: 10.1016/j.femsyr.2004.05.004

Qiagen (1993) 'TGGE Handbook.' (Qiagen Inc.: Chatsworth, CA)

Ramirez-Saad HC, Sessitsch A, Akkermans ADL (2003) Molecular diversity in the bacterial community and the fluorescent pseudomonads group in natural and chlorobenzoate-stressed peatforest soil. Microbiological Research 158, 47-54.

Rosenbaum V, Riesner D (1987) Temperature gradient gel electrophoresis: thermodynamic analysis of nucleic acids and proteins in purified form and in cellular extracts. Biophysical Chemistry 26, 235-246. doi: 10.1016/0301-4622(87)80026-1

Rozen S, Skaletsky HJ (2000) Primer3 on the WWW for general users and for biologist programmers. In 'Bioinformatics methods and protocols: methods in molecular biology'. (Eds S Krawetz, S Misener) pp. 365-386. (Humana Press: Totowa, NJ)

Saarikoski ST, Suitiala T, Holmila R, Impivaara O, Jarvisalo J, Hirvonen A, Husgafvel-Pursiainen K (2004) Identification of genetic polymorphisms of CYP2S1 in Finnish Caucasian population. Mutation Research Fundamental and Molecular Mechanisms of Mutagenesis 554, 267-277. doi: 10.1016/j.mrfmmm.2004.05.007

Savin MC, Martin JL, LeGresley M, Giewat M, Rooney-Varga J (2004) Plankton diversity in the Bay of Fundy as measured by morphological and molecular methods. Microbial Ecology 48, 51-65. doi: 10.1007/s00248-003-1033-8

Sekiguchi K, Saito H, Kasai K (2004) Mitrochondrial DNA heteroplasmy among hairs from single individuals. Journal of Forensic Sciences 49, 986-991.

Sheffield VC, Cox DR, Lerman LS, Myers RM (1989) Attachment of a 40-base-pair G+C-rich sequence (GC-clamp) to genomic DNA fragments by the polymerase chain reaction results in improving detection of single-base changes. Proceedings of the National Academy of Sciences of the United States of America 86, 232-236.

Soufi M, Schoppet M, Sattler AM, Herzum M, Maisch B, Hofbauer LC, Schaefer JR (2004) Osteoprotegerin gene polymorphism in men with coronary artery disease. Journal of Clinical Endocrinology and Metabolism 89, 3764-3768. doi: 10.1210/jc.2003-032054

Steger G (1994) Thermal denaturation of double-stranded nucleic acids: prediction of temperatures critical for gradient gel electrophoresis and polymerase chain reaction. Nucleic Acids Research 22, $2760-2768$.

Toliat MR, Erdogan F, Gewies A, Fahsold R, Buske A, Tinschert S, Nurnberg P (2000) Analysis of the NF1 gene by temperature gradient gel electrophoresis reveals a high incidence of mutations in exon 4b. Electrophoresis 21, 541-544. doi: 10.1002/(SICI)15222683(20000201)21:3<541::AID-ELPS541>3.0.CO;2-L

Westerdahl H, Wittzell H, von Schantz T, Bensch S (2004) MHC class I typing in a sondbird with numerous loci and high polymorphism using motif-specific PCR and DGGE. Heredity 92, 534-542. doi: 10.1038/sj.hdy. 6800450

White TJ, Bruns T, Lee S, Taylor JW (1990) Amplification and direct sequencing of fungal ribosomal RNA genes for phylogenetics. In 'PCR Protocols: a guide to methods and applications'. (Eds MA Innis, DH Gelfand, JJ Sninsky, TJ White) pp. 315-322. (Academic Press Inc.: New York, NY)

Xu P, Leff LG (2004) Longitudinal changes in the benthic bacterial community of the Mahoning River(Ohio, USA). Hydrobiologia 522, 329-335. doi: 10.1023/B:HYDR.0000029993.81246.63

Manuscript received 21 June 2004, accepted 27 January 2005 